\title{
Esophageal striated muscle contractions in patients with Chagas' disease and idiopathic achalasia
}

\section{R.O. Dantas, L.R.O. Aprile, \\ C.G. Aben-Athar \\ and A.L.M. Miranda}

Departamento de Clínica M édica, Faculdade de Medicina de Ribeirão Preto, Universidade de São Paulo, Ribeirão Preto, SP, Brasil

\section{Correspondence \\ R.O. Dantas \\ Departamento de Clínica Médica \\ FMRP, USP \\ 14049-900 Ribeirão Preto, SP Brasil \\ Fax: + 55-16-633-6695 \\ E-mail: rodantas@fmrp.usp.br \\ Research supported in part by Fundação de Apoio ao Ensino, Pesquisa e Assistência (FAEPA), Hospital das Clínicas, FM RP, USP, and FINEP (Pronex grant No. 42/97). Publication supported by FAPESP.}

Received July 17, 2001 Accepted April 1, 2002

\section{Abstract}

Chagas' disease causes degeneration and reduction of the number of intrinsic neurons of the esophageal myenteric plexus, with consequent absent or partial lower esophageal sphincter relaxation and loss of peristalsis in the esophageal body. The impairment of esophageal motility is seen mainly in the distal smooth muscle region. There is no study about esophageal striated muscle contractions in the disease. In 81 patients with heartburn (44 with esophagitis) taken as controls, 51 patients with Chagas' disease (21 with esophageal dilatation) and 18 patients with idiopathic achalasia (11 with esophageal dilatation) we studied the amplitude, duration and area under the curve of esophageal proximal contractions. Using the manometric method and a continuous perfusion system we measured the esophageal striated muscle contractions 2 to $3 \mathrm{~cm}$ below the upper esophageal sphincter after swallows of a 5-ml bolus of water. There was no significant difference in striated muscle contractions between patients with heartburn and esophagitis and patients with heartburn without esophagitis. There was also no significant difference between patients with heartburn younger or older than 50 years or between men and women or in esophageal striated muscle contractions between patients with heartburn and Chagas' disease. The esophageal proximal amplitude of contractions was lower in patients with idiopathic achalasia than in patients with heartburn. In patients with Chagas' disease there was no significant difference between patients with esophageal dilatation and patients with normal esophageal diameter. Esophageal striated muscle contractions in patients with Chagas' disease have the same amplitude and duration as seen in patients with heartburn. Patients with idiopathic achalasia have a lower amplitude of contraction than patients with heartburn.

\section{Introduction}

Chagas' disease, caused by the flagellate protozoan Trypanosoma cruzi, affects the esophageal myenteric plexus causing degeneration and reduction of the number of in-

\section{Key words}

- Esophageal contractions

- Chagas' disease

- Idiopathic achalasia

- Esophageal striated muscle 
Both diseases mainly involve the distal smooth muscle segment of the esophageal body, where there is a larger number of neurons in the myenteric plexus (1). However, there is also a reduction in the number of neurons in the myenteric plexus of the proximal third of the esophagus, where there is striated muscle $(1,3)$.

The contractions in the distal third of the esophagus are of low amplitude in Chagas' disease $(4,5)$ and in idiopathic achalasia $(5,6)$. The duration is longer than normal in idiopathic achalasia $(5,6)$, with results showing normal (5) or longer duration in Chagas' disease (7). A recent study described a low contraction amplitude with dry swallows in the esophageal striated muscle of patients with idiopathic achalasia (6). In Chagas' disease there is no similar study. We know that the filling rate of the proximal esophagus in patients with the disease after swallowing a 10-ml bolus of water is slower than in normal subjects as a consequence of a longer oral phase in Chagas' disease (8), a fact that might influence esophageal proximal contractions.

The objective of the present investigation was to study the esophageal striated muscle contractions in patients with Chagas' disease and compare them with those of patients with heartburn, taken as a control group, and patients with idiopathic achalasia.

\section{Material and Methods}

We retrospectively studied the esophageal striated muscle contractions of 81 patients who were submitted to esophageal manometric examination as part of the evaluation of heartburn, 51 patients with Chagas' disease, and 18 patients with idiopathic achalasia. The manometric examinations were performed from 1999 through 2001 as a contribution to the diagnosis of the diseases.

All patients with heartburn (control group: 31 men and 50 women aged 17 to 87 years, median 41 years) were submitted to endo- scopic examination which showed a normal esophagus in 37 and esophagitis in 44 (grade I in 28, grade II in 7, and grade IV in 3 according to the classification of SavaryMiller), and Barrett esophagus in 6. Patients with dysphagia, chest pain, previous surgical treatment of gastroesophageal reflux disease, chronic cough, globus, esophageal stricture, laryngitis, pulmonary disease, and connective tissue diseases were excluded from the study. No patient had endocrine diseases or abnormalities in the manometric examination of the distal esophagus, with amplitude of contractions ranging from 35 to 180 $\mathrm{mmHg}$, and more than $90 \%$ of swallows being followed by peristaltic contractions (9). In this group, which we used as control, we compared patients with esophagitis $(\mathrm{N}=$ 44) with patients without esophagitis $(\mathrm{N}=$ 37), patients aged 17 to 49 years (median: 37 years, $\mathrm{N}=52$ ) with patients aged 50 to 87 years (median: 61 years, $N=29$ ), and men $(\mathrm{N}=31)$ with women $(\mathrm{N}=50)$.

The patients with Chagas' disease (Chagas group) had a positive immunofluorescence test for $T$. cruzi. They were 19 men and 32 women aged 23 to 82 years, median 62 years. Radiologic esophageal examination showed that 30 patients had a normal diameter, 21 of them with slow transit, and 21 had an increase in esophageal diameter. No patient had been submitted to previous treatment. Dysphagia was a complaint in all patients with dilatation and in 25 without dilatation.

All patients with idiopathic achalasia (achalasia group) had dysphagia. They were 10 men and 8 women aged 12 to 68 years, median 38 years. Eleven patients had esophageal dilatation in the radiologic examination, and 7 had only retention and slow transit. They had partial or absent LES relaxation and aperistalsis in the distal esophageal body. None had been submitted to previous treatment. All had a negative immunofluorescence test for $T$. cruzi.

In the manometric examination we used a round eight-lumen polyvinyl catheter 
(Arndorfer Specialties Inc., Greendale, WI, USA) with an outer diameter of $4.5 \mathrm{~mm}$ and an internal diameter of $0.8 \mathrm{~mm}$ for each lumen. The four proximal lateral openings of the catheter were spaced $5 \mathrm{~cm}$ apart at 90 degree angles and the four distal openings were at the same level. For the manometric examination we used the four proximal channels and one distal channel, for a total of five channels spaced $5 \mathrm{~cm}$ apart. The channels were connected to five external pressure transducers (pvb Medizintechnik GmbH, Kirchseeon, Germany) with output to a PC Polygraph HR (Synectics Medical, Stockholm, Sweden). The manometric assembly was continuously perfused with water at a flow rate of $0.5 \mathrm{ml} / \mathrm{min}$ provided by a low compliance perfusion system (JS Biomedicals Inc., Ventura, CA, USA).

The examination was performed during the morning after at least $12 \mathrm{~h}$ of fasting. The catheter was introduced through the nose until at least four side holes reached the stomach. After $10 \mathrm{~min}$ of stabilization the catheter was pulled at $1-\mathrm{cm}$ intervals and at each station the patient swallowed a 5-ml bolus of water at room temperature. The esophagus was studied from the LES to the upper esophageal sphincter (UES). The esophageal segment $5 \mathrm{~cm}$ below the UES was defined as the striated muscle region of the esophageal body.

We measured the maximum striated muscle contraction through the proximal side hole of the catheter (6) consequent to one wet swallow when this side hole was at 2 or $3 \mathrm{~cm}$ below the UES. We analyzed the amplitude, duration and area under the curve (AUC) of the contractions with a computer program (Polygram for Windows 2.0 Medtronic Synectics, Stockholm, Sweden).

We used one-way analysis of variance and the Tukey-Kramer multiple comparisons test for the statistical evaluation of the results, with the level of significance set at $\mathrm{P}<0.05$. Data are reported as means $\pm \mathrm{SD}$ and median.

\section{Results}

The Kolmogorov-Smirnov test applied to the results showed that the data followed Gaussian distribution in all groups.

In the group of patients with heartburn we studied the effect of esophagitis, age and gender on amplitude, duration and AUC of the contractions. There were no differences between men and women, between patients older and younger than 50 years or between patients with or without esophagitis $(\mathrm{P}>0.05)$. The amplitude of contractions was $106.3 \pm$ $45.0 \mathrm{mmHg}$ in patients with esophagitis $(\mathrm{N}=$ 44) and $100.8 \pm 36.7 \mathrm{mmHg}$ in patients with normal endoscopy $(\mathrm{N}=37)$.

The amplitude of contractions was lower $(\mathrm{P}<0.01)$ in patients with idiopathic achalasia than in patients with heartburn (Figure 1). There were no differences between the three groups studied $(\mathrm{P}>0.05)$ in the duration (Figure 2) or AUC (Figure 3) of contractions.

The striated muscle contractions of patients with Chagas' disease did not differ $(\mathrm{P}>0.05)$ from those observed in the other groups (Table 1). Also, the patients with esophageal dilatation did not differ $(\mathrm{P}>0.05)$

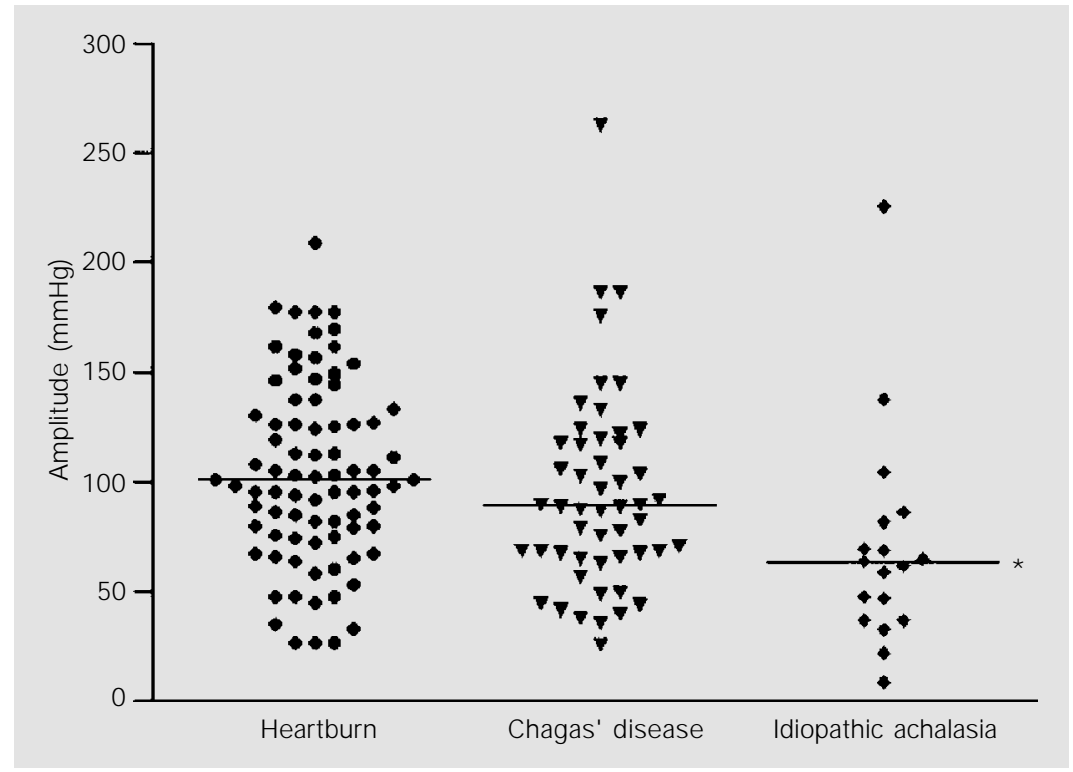

Figure 1. Amplitude of esophageal striated muscle contractions in patients with heartbum, Chagas' disease or idiopathic achalasia. The horizontal lines indicate the medians. $* \mathrm{P}<0.01$ compared to heartbum (Tukey-Kramer test). 
from patients without dilatation (Table 2).

Although the results suggest that the patients with idiopathic achalasia might have lower AUC than the control group, the difference was not statistically significant $(\mathrm{P}=$ $0.07)$.

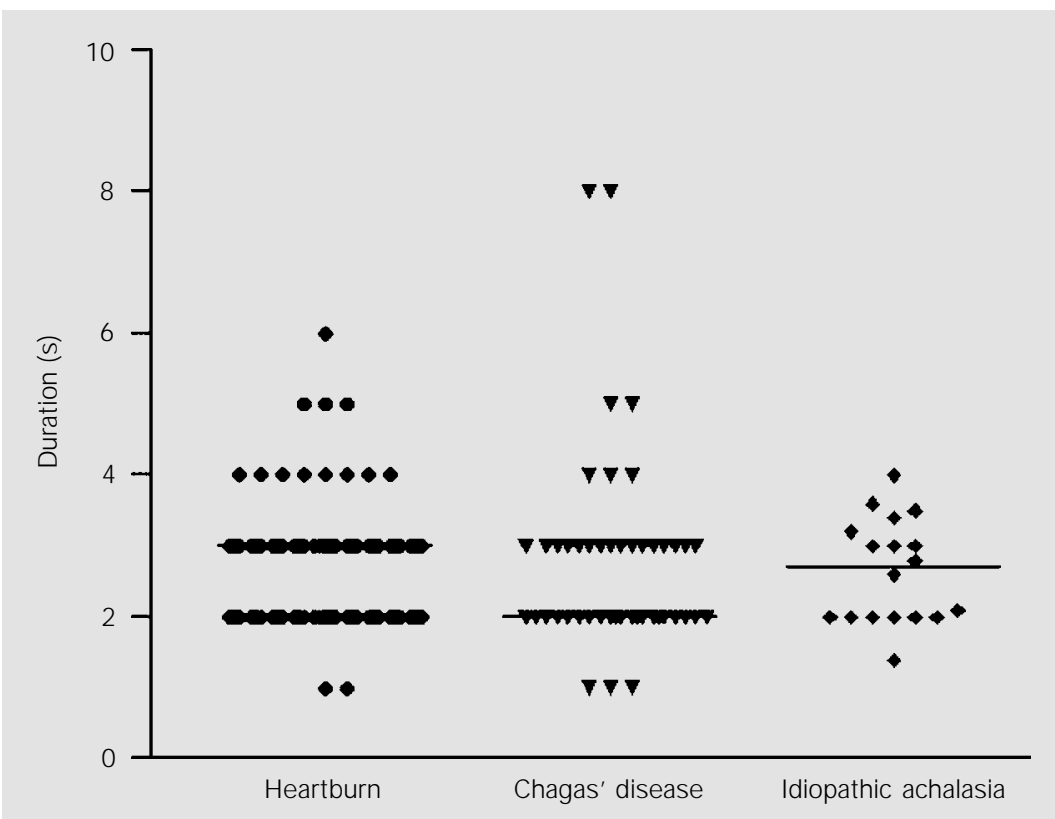

Figure 2. Duration of esophageal striated muscle contractions in patients with heartburn, Chagas' disease or idiopathic achalasia. The horizontal lines indicate the medians.

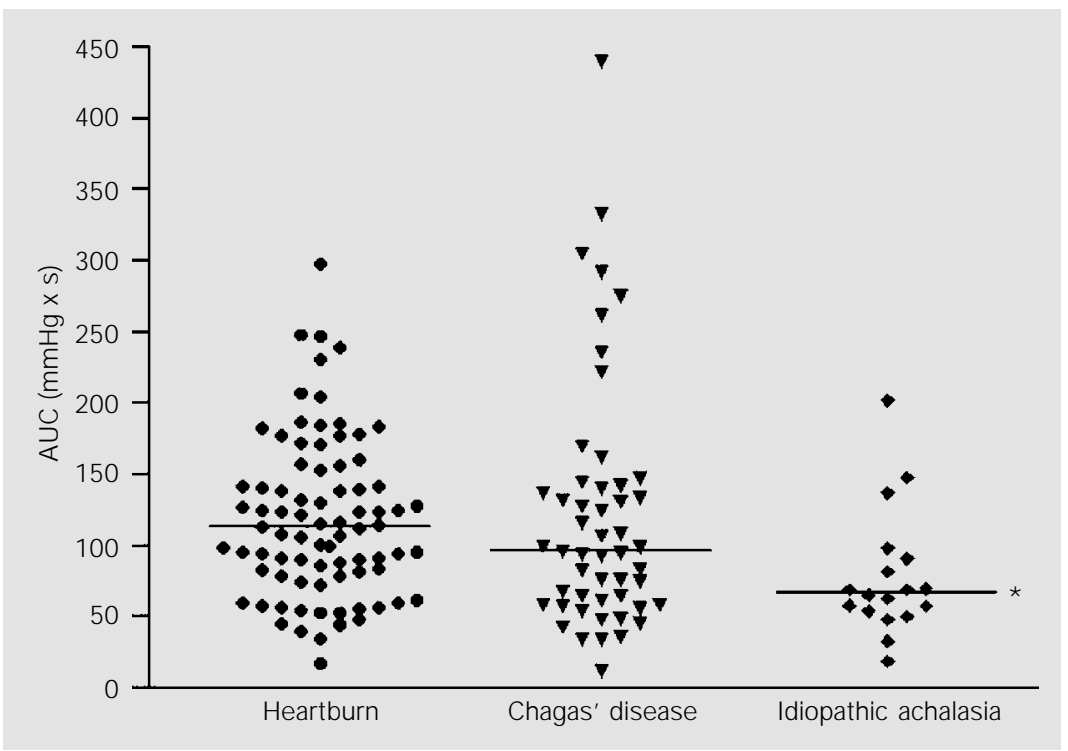

Figure 3. Area under the curve (AUC) of esophageal striated muscle contractions in patients with heartbum, Chagas' disease or idiopathic achalasia. The horizontal lines indicate the medians. $* \mathrm{P}=0.07$ compared to heartbum (Tukey-Kramer test).

\section{Discussion}

We did not find differences in the striated esophageal muscle contractions of patients with Chagas' disease compared with patients with heartburn or patients with idiopathic achalasia.

The most important histological finding in Chagas' disease and idiopathic achalasia is the reduction in the number of neurons of the esophageal myenteric plexus. Ganglion cells rarely appear and are sparse in the myenteric plexus below the level of the cricoid cartilage $(1,10)$. They continuously increase in number up to the middle portion and then maintain approximately the same number up to the cardia (1). The reduction of myenteric ganglion cells occurs along the entire length of the esophagus both in idiopathic achalasia (3) and in Chagas' disease (1).

The contractions of esophageal striated muscle are related to the extrinsic innervation (10). The extrinsic motor nerves to the striated muscle regions innervate muscle cells through motor end-plates. The neurotransmitter released at the end-plates is acetylcholine, which activates nicotinic cholinergic receptors in striated muscle (10). The neurons in the myenteric plexus of this region play a lesser role in the control of esophageal peristalsis than the myenteric plexus of the smooth muscle region.

The cell bodies that send somatic nerves to the striated muscle region of the esophageal body are situated in the rostral nucleus ambiguus (10). Motor neurons cross the vagi to innervate this muscle. A very proximal bilateral vagotomy abolishes peristalsis in this segment of the esophageal body. Sensory afferent inputs modulate the central vagal output that controls the peristaltic contractions. Studies indicate that in Chagas' disease (1) and idiopathic achalasia (3) the predominant abnormalities exist within the myenteric plexus, but loss of neurons within the dorsal motor nucleus and degenerative changes of the vagal nerve fibers have been 
noted (11-13). The results of the study of proximal amplitude suggested that these alterations may be more important in idiopathic achalasia than in Chagas' disease.

Patients with esophageal dilatation should have a low amplitude of contractions as a consequence of the increase in the diameter of the organ. However, this was not observed in the present study, perhaps because the diameter of the esophageal body was not increased in the upper esophagus a few centimeters from the UES.

A previous study found a lower maximum striated muscle contraction amplitude in patients with achalasia than in controls in response to dry swallows (6). The results of the present study show that the amplitude of contractions in patients with achalasia is indeed decreased. We studied wet swallows, which may cause a higher amplitude than the dry swallows used in the previous study (6), as seen in esophageal smooth muscle contractions (5). Another study using wet swal- lows detected a lower contraction amplitude and longer contraction duration in patients with achalasia than in controls, measured 3 $\mathrm{cm}$ below the UES (14). As our results with wet swallows suggested the same conclusion when the contractions were studied with dry and wet swallows, we believe that the striated esophageal muscle contraction in achalasia is decreased. With these results we may assume that esophageal motor involvement by Chagas' disease differs somewhat from the involvement by idiopathic achalasia. Differences in the smooth muscle segment of the esophagus (5) and in LES pressure $(5,15)$, but not in UES pressure (16), have been reported.

We studied proximal esophageal striated muscle contractions 2 or $3 \mathrm{~cm}$ below the UES. One study in humans showed that the area in which striated and smooth muscle portions were approximately equal was 4.7 $\pm 0.6 \mathrm{~cm}$ from the proximal portion of the cricopharyngeal muscle (17). This is the tran-

Table 1. Esophageal striated muscle contractions of patients with heartbum, Chagas' disease or idiopathic achalasia.

\begin{tabular}{lccc}
\hline & Amplitude $(\mathrm{mmHg})$ & Duration $(\mathrm{s})$ & AUC $(\mathrm{mmHg} \times \mathrm{s})$ \\
\hline Heartbum $(\mathrm{N}=81)$ & $103.8 \pm 41.3(101.0)$ & $2.7 \pm 0.8(3.0)$ & $119.0 \pm 56.0(113.4)$ \\
Chagas' disease $(\mathrm{N}=51)$ & $94.3 \pm 44.9(89.0)$ & $2.7 \pm 1.4(2.0)$ & $121.7 \pm 87.9(95.7)$ \\
Achalasia $(\mathrm{N}=18)$ & $69.9 \pm 49.5(63.1)^{*}$ & $2.6 \pm 0.8(2.5)$ & $78.6 \pm 44.4(67.2)^{* *}$ \\
\hline
\end{tabular}

AUC $=$ area under the curve. Data are reported as means \pm SD and (medians).

$* \mathrm{P}<0.01$ and $* * \mathrm{P}=0.07$ compared to heartbum (Tukey-Kramer test).

Table 2. Esophageal striated muscle contractions of patients with Chagas' disease and idiopathic achalasia with normal esophageal diameter or with esophageal dilatation.

\begin{tabular}{llll}
\hline & Amplitude $(\mathrm{mmHg})$ & Duration $(\mathrm{s})$ & AUC $(\mathrm{mmHg} \times \mathrm{s})$ \\
\hline $\begin{array}{l}\text { Chagas' disease } \\
\quad\end{array}$ & & \\
$\quad$ Normal $(\mathrm{N}=30)$ & $90.5 \pm 39.3(87.6)$ & $2.5 \pm 0.9(2.4)$ & $112.2 \pm 69.0(107.2)$ \\
$\quad$ Dilatation $(\mathrm{N}=21)$ & & $2.9 \pm 1.8(2.3)$ & $135.1 \pm 110.1(94.8)$ \\
Achalasia & & & \\
$\quad$ Normal $(\mathrm{N}=7)$ & $53.4 \pm 27.0(47.9)$ & $2.8 \pm 0.7(2.8)$ & $70.6 \pm 40.9(63.0)$ \\
$\quad$ Dilatation $(\mathrm{N}=11)$ & $80.4 \pm 58.4(63.8)$ & $2.1 \pm 1.5(2.1)$ & $83.7 \pm 47.7(68.8)$ \\
\hline
\end{tabular}

AUC $=$ area under the curve. Data are reported as means \pm SD and (medians). 
sition zone and has the lowest esophageal amplitude of contraction, described as a "pressure trough". In another study this area was located at $21.7 \pm 1.3 \%$ of the esophageal length (18). Below this transition the proportion of smooth muscle increases progressively until the middle esophagus, where the muscle is exclusively smooth (17). We performed the measurement at a site that has more than $50 \%$ of striated muscle.

The manometric behavior of the striated muscle portion of the proximal esophagus shows characteristics similar to those of distal esophageal smooth muscle and different from the striated muscle of the pharynx (19). The slower contraction of the striated esophageal muscle than the striated muscle of the pharynx makes our perfusion system adequate to measure contraction. With the rapid contraction of the pharynx a solid state cath- eter is required.

We did not detect differences caused by esophagitis, age or gender in the control group. Esophagitis was located in the distal esophagus where it can cause failed and low contraction amplitudes (20). The proximal esophageal contraction did not differ between patients with gastroesophageal reflux symptoms with or without esophagitis, with or without dysphagia or with moderate or severe esophagitis (21). We did not include patients with lesions or symptoms suggestive of involvement of the proximal esophagus in the control group.

Esophageal striated muscle contractions seem to be normal in Chagas' disease and to have the same spectrum as seen in patients with heartburn. In idiopathic achalasia the proximal esophageal contraction is of low amplitude.

\section{References}

1. Köberle F (1968). Chagas' disease and Chagas' syndromes: The pathology of American trypanosomiasis. Advances in Parasitology, 6: 63-116.

2. Oliveira RB, Troncon LEA, Dantas RO \& Meneghelli UG (1998). Gastrointestinal manifestations of Chagas' disease. American J ournal of Gastroenterology, 93: 884889.

3. Goldblum J R, Whyte RI, Oringer MB \& Appelman HD (1994). Achalasia. A morphologic study of 42 resected specimens. American J ournal of Surgical Pathology, 18: 327-337.

4. Oliveira RB, Rezende Filho J , Dantas RO $\&$ lazigi N (1995). The spectrum of esophageal motor disorders in Chagas' disease. American J ournal of Gastroenterology, 90: 1119-1124.

5. Dantas RO, Deghaide NHS \& Donadi EA (2001). Esophageal motility of patients with Chagas' disease and idiopathic achalasia. Digestive Diseases and Sciences, 46: 1200-1206.

6. Dunaway PM, Maydonovitch $\mathrm{CL} \&$ Wong RKH (2000). Characterization of esophageal striated muscle in patients with achalasia. Digestive Diseases and Sci- ences, 45: 285-288.

7. Dantas RO (1998). Dysphagia in patients with Chagas' disease. Dysphagia, 13: 5357.

8. Souza MAN, Dantas RO, Oliveira RB \& Braga FJ HN (2000). A scintigraphic study of oropharyngeal swallowing dynamics in Chagas' disease. Neurogastroenterology and Motility, 12: 335-341.

9. Kahrilas PJ, Clouse RE \& Hogan WJ (1994). American Gastroenterological Association technical review on the clinical use of esophageal manometry. Gastroenterology, 107: 1865-1884

10. Conklin J L \& Christensen J (1994). Motor functions of the pharynx and esophagus. In: J ohnson LR (Editor), Physiology of the Gastrointestinal Tract. 3rd edn. Raven Press, New York, NY, USA, 903-928.

11. Lopes ER, Tafuri WL \& Chapadeiro E (1969). Estudo morfológico e quantitativo dos núcleos dorsal do vago e hipoglosso em chagásicos crônicos com e sem megaesôfago. Revista do Instituto de Medicina Tropical de São Paulo, 11: 123129.

12. Cassella R, Brown A, Sayre $G \&$ Ellis $F$ (1964). Achalasia of the esophagus: patho- logic and etiologic considerations. Annals of Surgery, 160: 474-487.

13. Hirano I (1999). Pathophysiology of achalasia. Current Gastroenterology Reports, 1: 198-202.

14. Zelter A, Bilder C, Ortubey $G$, Feiguelman L, Iantorno G \& Sifrim D (1999). Peristalsis in the striated muscle portion of the esophagus in achalasia. Neurogastroenterology and Motility, 11: 303 (Abstract).

15. Dantas RO, Godoy RA, Oliveira RB, Meneghelli UG \& Troncon LEA (1990). Lower esophageal sphincter pressure in Chagas' disease. Digestive Diseases and Sciences, 35: 508-512.

16. Dantas RO (2000). Upper esophageal sphincter pressure in patients with Chagas' disease and primary achalasia. Brazilian J ournal of Medical and Biological Research, 33: 545-551.

17. Meyer GW, Austin RM, Brady CE \& Castell DO (1986). Muscle anatomy of the human esophagus. J ournal of Clinical Gastroenterology, 8: 131-134.

18. Clouse RE \& Staiano A (1991). Topography of the esophageal pressure wave. American J ournal of Physiology, 261: G677-G684. 
19. Peghini PL, Pursnani KG, Gideon MR, Castell J A, Nierman J \& Castell DO (1998). Proximal and distal esophageal contractions have similar manometric features. American J ournal of Physiology, 274: G325-G330.
20. Kahrilas PJ, Dodds WJ, Hogan WJ, Kem M, Arndorfer RC \& Reece A (1986). Esophageal peristaltic dysfunction in peptic esophagitis. Gastroenterology, 91: 897-904.

21. Dantas RO \& Aprile LRO (2001). Oesoph- ageal striated muscle contractions in patients with gastro-oesophageal reflux symptoms. Neurogastroenterology and Motility, 13: 384-385 (Abstract). 